\title{
Platelet release protein which inhibits plasminogen activators
}

\author{
NUALA A BOOTH, JUDITH A ANDERSON, BRUCE BENNETT \\ From the Department of Medicine, University of Aberdeen, Aberdeen Royal Infirmary, Aberdeen, Scotland
}

SUMMARY An inhibitor of plasminogen activator has been identified in human platelets by the technique of sodium dodecyl sulphate polyacrylamide gel electrophoresis and zymography. The inhibitor has a molecular weight of about 40000 and is distinct from known plasma protease inhibitors. It is associated almost exclusively with platelets, with only trace amounts in platelet free plasma. The inhibitor is released during platelet aggregation or in vitro coagulation. This inhibitor inhibits both tissue type plasminogen activator and urokinase but has no effect on plasmin. It forms a 1:1 complex with tissue type plasminogen activator, which retains activity detectable under the analytical conditions used. A similar complex with urokinase either forms less readily or retains less activity.

The activation of plasminogen to plasmin by plasminogen activators (PA) is central to the process of fibrinolysis, in which plasmin digests the insoluble fibrin matrix of thrombi to form soluble products. The activity of plasmin thus formed is controlled by its major plasma inhibitor, $\alpha_{2}$-antiplasmin; free plasmin in the circulation is neutralised immediately by this inhibitor.' The existence of specific inhibitors of PA has been disputed for many years. The major reason for the controversy has been the technical difficulty of distinguishing between inhibitors of PA and inhibitors of plasmin. In the past two years evidence has been accumulating for the existence of an inhibitor of PA in plasma. The existence of this inhibitor was suggested by the finding that when low concentrations of purified tissue type PA (t-PA) were added to plasma losses of PA activity could be detected..$^{2-4}$ An endothelial cell inhibitor of PA has also been described. ${ }^{5}$ This inhibitor was detected in samples separated by sodium dodecyl sulphate polyacrylamide gel electrophoresis (SDS-PAGE) and analysed for inhibition of PA in a fibrin/ plasminogen/PA detector gel. ${ }^{6}$ The same technique was used to analyse normal human plasma for inhibitors of the fibrinolytic system, and we found that the only inhibitor specific for PA present in plasma had a molecular weight of about $40 \mathrm{~K} .^{7}$ In this paper we report that this plasma inhibitor of PA is present mainly in platelets and is released from platelets by all known aggregating agents. We also report on its interactions with both $t-P A$ and urokinase PA (u-PA).

Accepted for publication 27 March 1985

\section{Material and methods}

\section{BLOOD SAMPLES}

Blood samples were collected into $0 \cdot 1$ vol of $0 \cdot 13 \mathrm{M}$ sodium citrate. Platelet free plasma was prepared by centrifugation at $1850 \mathrm{~g}$ for $30 \mathrm{~min}$ at $4^{\circ} \mathrm{C}$ and platelet poor plasma was prepared by centrifugation at $1000 \mathrm{~g}$ for $15 \mathrm{~min}$ at $4^{\circ} \mathrm{C}$. Serum was similarly prepared from blood, collected into glass tubes containing no anticoagulant, and incubated at $37^{\circ} \mathrm{C}$ for $30 \mathrm{~min}$ before centrifugation. Platelet rich plasma was prepared by centrifugation at $170 \mathrm{~g}$ for $10 \mathrm{~min}$ at $20^{\circ} \mathrm{C}$. Platelets were prepared from platelet rich plasma by centrifugation at $1850 \mathrm{~g}$ for $15 \mathrm{~min}$ at room temperature and resuspended in $0.9 \%$ (wt/ vol) aqueous sodium chloride. All plasma and serum samples were stored at $-70^{\circ} \mathrm{C}$.

\section{PLATELET COUNTING}

Platelets were counted in plasma samples using a Coulter Thrombocounter C.

\section{PLATELET AGgREGATION}

Platelet rich plasma was aggregated by incubation at $37^{\circ} \mathrm{C}$ for $5 \mathrm{~min}$ with adenosine diphosphate (ADP) $(2.5 \mu \mathrm{M})$, collagen $(2.5 \mu \mathrm{g} / \mathrm{ml})$, ristocetin $(3.0 \mathrm{mg} /$ $\mathrm{ml})$, or thrombin $(0.5 \mathrm{U} / \mathrm{ml})$, all final concentrations, and centrifuged at $1000 \mathrm{~g}$ for $15 \mathrm{~min}$ at $4^{\circ} \mathrm{C}$.

\section{GEL FILTRATION}

The method used was based on that of Tangen. ${ }^{8}$ Platelet rich plasma $(3 \mathrm{ml})$ was applied to a column of Sepharose 2B $(1.6 \times 30 \mathrm{~cm})$ and eluted with 140 
$\mathrm{mM}$ sodium chloride, $13 \mathrm{mM}$ sodium citrate at room temperature. The eluate was monitored for PA inhibitory activity by zymography, for absorbance at $280 \mathrm{~nm}$ and platelet count.

\section{PLATELET LYSATES}

Platelets, separated from platelet rich plasma by gel filtration, were lysed at maximum setting in a MSE ultrasonic disintegrator Model $150 \mathrm{~W}$, using 3-5 s bursts with $1 \mathrm{~min}$ intervals.

\section{ZYMOGRAPHIC METHODS}

SDS-PAGE with zymography on fibrin-agarose layers was based on the method of Granelli-Piperno and Reich." PA activity in samples separated by SDS-PAGE was visualised on a detector gel containing fibrin and plasminogen. PA activates the plasminogen to plasmin, which lyses the opaque fibrin layer and produces clear bands of lysis. This method was adapted for detection of inhibitory activity, ${ }^{5}$ as described previously, ${ }^{7}$ by additionally incorporating into the detector gel sufficient PA (either t-PA or u-PA) to cause lysis of the entire gel in $16 \mathrm{~h}$. Inhibitor bands are detectable as opaque bands of fibrin, resistant to lysis, in an otherwise clear detector gel. For both zymographic methods samples $(10 \mu \mathrm{l})$ were prepared for SDS-PAGE by incubation with $10 \mu \mathrm{l}$ of sample buffer $(8 \mathrm{M}$ urea, $4 \%$ SDS, $40 \mathrm{mM}$ iodoace tamide, $0.2 \mathrm{M}$ Tris, $\mathrm{pH} 8.0$ )

v for $30 \mathrm{~min}$ at $37^{\circ} \mathrm{C}$ and then made $10 \%$ with respect to glycerol. They were applied to a Laemmli gel $^{10}$ (separating and stacking gels were $10 \%$ and $3 \%$ acrylamide respectively; gel measured $180 \times 200 \times$ $1.2 \mathrm{~mm}$ ) and run at $20 \mathrm{~mA}$ for $3.5 \mathrm{~h}$. The gel was washed for $1 \mathrm{~h}$ in 1 litre of $2.5 \%$ aqueous Triton $\mathrm{X}-100$ with constant agitation and rinsed repeatedly with distilled water before it was applied to a $1 \cdot 3$ $\mathrm{mm}$ thick detector gel, which contained the following: fibrinogen (Kabi L) $2 \mathrm{mg} / \mathrm{ml}$; plasminogen (a contaminant of the fibrinogen) $2 \cdot 0-3 \cdot 0 \mu \mathrm{g} / \mathrm{ml}$; thrombin $0.06 \mathrm{U} / \mathrm{ml} ; 17.5 \mathrm{mM}$ sodium chloride; 60 $\mathrm{mM}$ Tris, $\mathrm{pH} 7.8 ; 0.8 \%$ agarose (all final concentrations). For detection of inhibitors the fibrin gels also contained either u-PA (Leo urokinase) 0.075 Ploug units $/ \mathrm{ml}$ or t-PA, prepared from human heart tissue, ${ }^{11} 0.035$ NIBSC units $/ \mathrm{ml}$. In control experiments plasmin (Kabi) $0.005 \mathrm{CU} / \mathrm{ml}$ was incorporated in the gels in place of PA plus plasminogen. After $16 \mathrm{~h}$ at $37^{\circ} \mathrm{C}$ the polyacrylamide gel was removed and the detector gel photographed.

\section{Results}

Normal platelet poor plasma, when analysed for inhibitors by SDS-PAGE plus zymography, showed two bands of inhibition at $75 \mathrm{~K}$ and $40 \mathrm{~K}$ molecular weight. The $75 \mathrm{~K}$ band was identified previously as $\alpha_{2}$-antiplasmin using plasma specifically depleted of this protein by immunoadsorption. ${ }^{7}$ The $40 \mathrm{~K}$ inhibitor showed variable and often weak inhibitory activity in platelet poor plasma and showed consistently stronger activity in serum than in plasma samples. Strong inhibition was seen at $40 \mathrm{~K}$ when platelet rich plasma or washed platelet suspensions

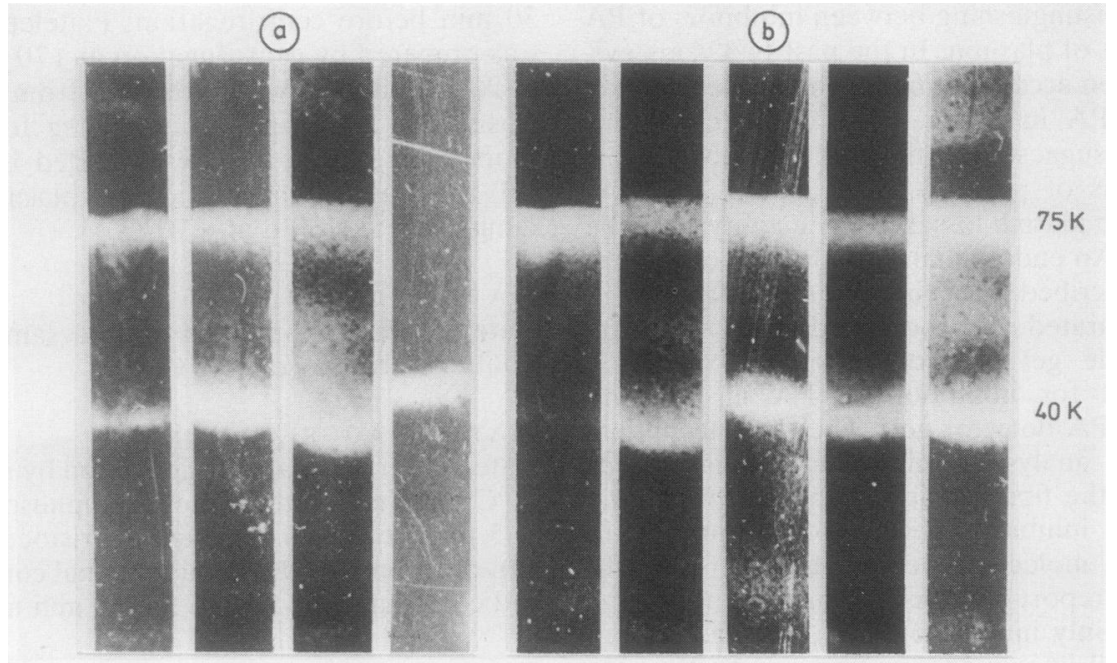

Fig. 1 Analysis of samples for inhibition of urokinase mediated lysis of fibrin. Samples (10 $\mu$ l) were: (a) (left to right) platelet poor plasma (platelet count $20 \times 10^{4} / \mathrm{l}$ ); platelet rich plasma (platelet count $320 \times 10^{4} / \mathrm{l}$ ); serum; platelet suspension (platelet count $\left.150 \times 10^{4} / \mathrm{l}\right)$; and $(\mathrm{b})$ supernatants from incubations of platelet rich plasma with (left to right) sodium chloride (control); ADP; ristocetin; thrombin; collagen. 
were analysed (Fig. 1a). These observations suggested that it was released from platelets during clot formation. This was tested by aggregation of platelet rich plasma with ADP, collagen, ristocetin, or thrombin. In all cases aggregation was associated with release of the inhibitor into the supernatant (Fig. 1b).

The distribution of the $40 \mathrm{~K}$ inhibitor in blood was examined by gel filtration of platelet rich plasma on Sepharose 2B. More than $95 \%$ of this inhibitor was associated with the platelet fraction, with only a trace in the plasma protein peak, in which $\alpha_{2-}$ antiplasmin was easily detected (Fig. 2a). When the same platelet rich plasma was aggregated before gel filtration and the corresponding fractions analysed the $40 \mathrm{~K}$ inhibitor, released on aggregation, was present in the protein peak (Fig. 2b).

The specificity of the $40 \mathrm{~K}$ inhibitor for PA was examined by comparing the inhibition found in platelets and plasma when the detector gel was lysed by u-PA plus plasminogen, t-PA plus plasminogen, or preformed plasmin. Inhibition of u-PA or t-PA mediated lysis was seen at $40 \mathrm{~K}$, although inhibition of t-PA was apparently weak in this system (Fig. 3). In contrast, the $40 \mathrm{~K}$ protein had no inhibitory effect when the detector gel was lysed by preformed plasmin; only $\alpha_{2}$-antiplasmin was inhibitory under these conditions. The difference in molecular size between the inhibitor band in plasma and in plasma free platelet suspensions is due to the high protein concentrations in the plasma samples, which causes dragging of the bands in these samples. ${ }^{12}$

Purified t-PA or u-PA was incubated with increasing concentrations of sonicated, gel filtered platelets for $5 \mathrm{~min}$ at $37^{\circ} \mathrm{C}$ and these mixtures were analysed for PA activity by SDS-PAGE and zymography. Even at low concentrations of sonicated platelets an additional band of $\mathrm{t}-\mathrm{PA}$ related activity was seen at about $110 \mathrm{~K}$ (Fig. 4), consistent with formation of a $1: 1$ complex between $\mathrm{t}-\mathrm{PA}(65 \mathrm{~K})$ and the $40 \mathrm{~K}$

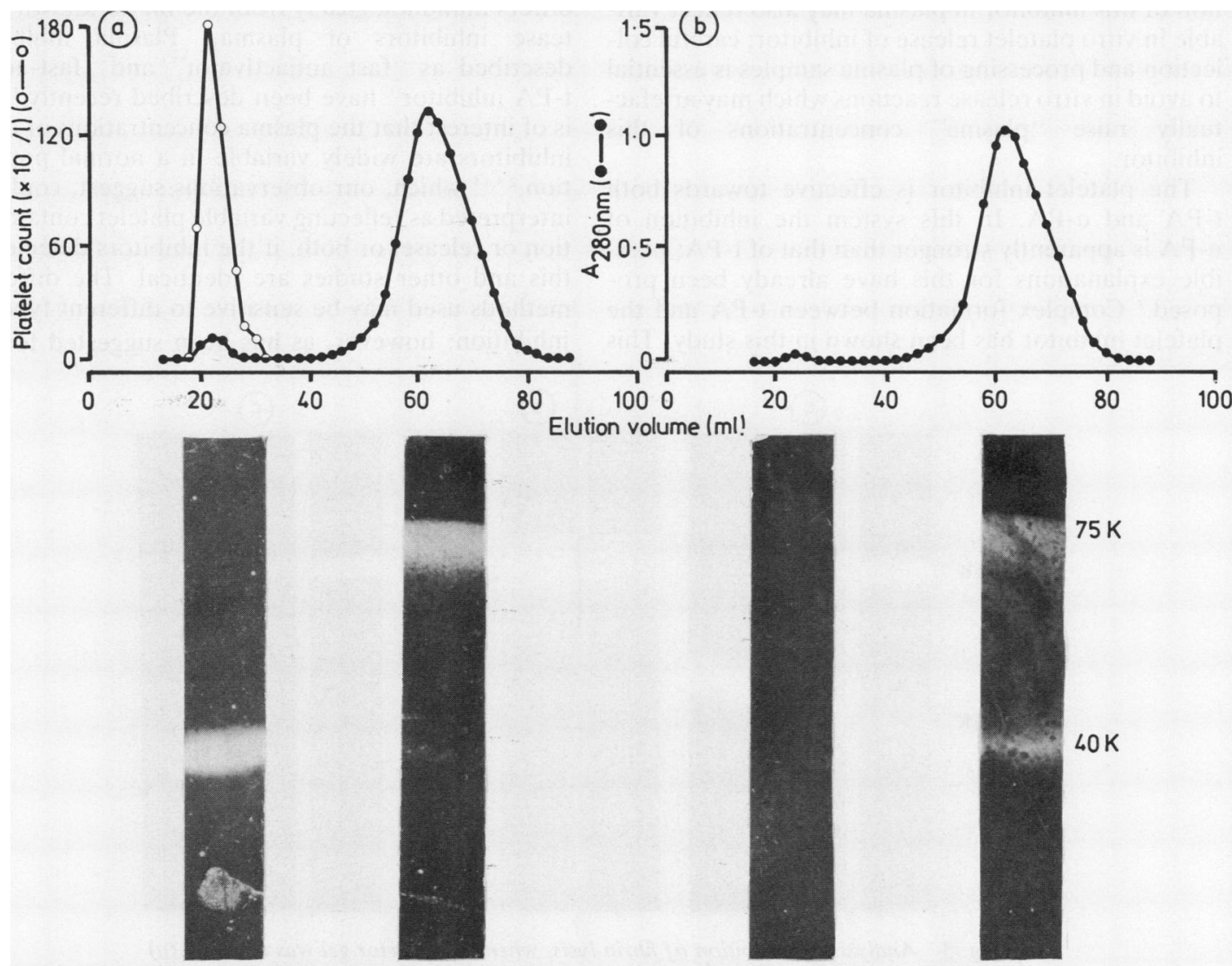

Fig. 2 (a) Platelet rich plasma $(3 \mathrm{ml})$ was separated on Sepharose $2 B(1.6 \times 30 \mathrm{~cm})$. (b) The same sample of platelet rich plasma was aggregated with $0.5 \mathrm{U} / \mathrm{ml}$ of thrombin before gel filtration. The gels show analysis of the platelet and protein peaks for inhibition of urokinase mediated lysis of fibrin. 
platelet inhibitor. No evidence for complex formation between u-PA and the inhibitor was found (Fig. 4) except where the concentration of platelet lysate was greatly increased and an extremely faint band of high molecular weight activity was just visible (not illustrated). These data are consistent either with relatively poor formation of a complex between u-PA and the platelet inhibitor or low activity of such a complex in the analytical system used.

\section{Discussion}

We have shown that the $40 \mathrm{~K}$ inhibitor of PA, detectable in plasma by a zymographic technique, ${ }^{7}$ is a platelet protein. The presence of low and variable inhibitory activity at $40 \mathrm{~K}$ in platelet poor plasma probably reflects variation in numbers of contaminating platelets. In this system platelets in the sample are lysed during incubation in the SDS buffer; prior disruption is not required. Variable detection of this inhibitor in plasma may also reflect variable in vitro platelet release of inhibitor; careful collection and processing of plasma samples is essential to avoid in vitro release reactions which may artefactually raise "plasma" concentrations of this inhibitor.

The platelet inhibitor is effective towards both t-PA and u-PA. In this system the inhibition of $\mathrm{u}-\mathrm{PA}$ is apparently stronger than that of t-PA; possible explanations for this have already been proposed. ${ }^{7}$ Complex formation between t-PA and the platelet inhibitor has been shown in this study. This complex retains some PA activity as has been noted previously for other protease inhibitor complexes." The complex is of the same molecular weight as the t-PA complex which is present in normal plasma. ${ }^{13}$ Thus this platelet inhibitor may have a role in the regulation of normal t-PA activity in the circulation. It is interesting that a complex between u-PA and this inhibitor either occurs less readily or is less active in the zymographic system. This is consistent with the situation in resting normal plasma, where u-PA activity is present at $50 \mathrm{~K}$, the molecular weight of free u-PA, while the t-PA activity is present at $110 \mathrm{~K}$, suggesting its presence as a complex. Even in the plasma of patients with alcoholic cirrhosis, where both t-PA and u-PA are increased, only free u-PA activity is detectable, while t-PA is present in both free and complexed forms. ${ }^{13}$

The relation between this inhibitor and other inhibitors of t-PA and u-PA is not yet established. In studies reported elsewhere we have shown that it differs immunologically from the major known protease inhibitors of plasma." Plasma inhibitors described as "fast antiactivator" and "fast-acting t-PA inhibitor" have been described recently. ${ }^{2-4}$ It is of interest that the plasma concentrations of these inhibitors are widely variable in a normal population, ${ }^{2.314}$ which, our observations suggest, could be interpreted as reflecting variable platelet contamination or release, or both, if the inhibitors detected in this and other studies are identical. The different methods used may be sensitive to different types of inhibition; however, as has been suggested for the

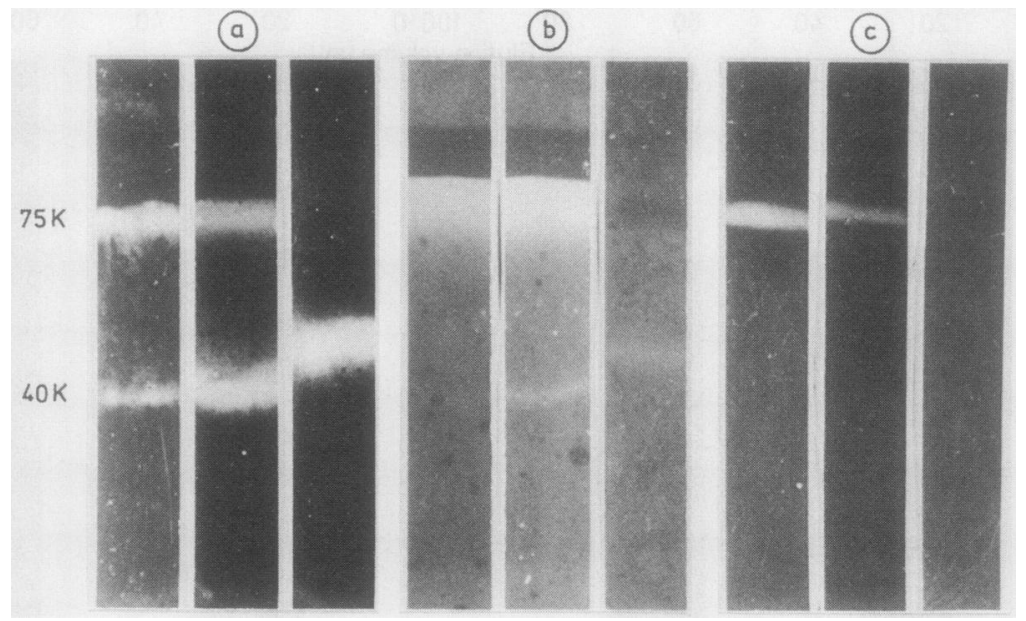

Fig. 3 Analysis of inhibition of fibrin lysis, when the detector gel was lysed by (a) urokinase; (b) tissue type plasminogen activator, or (c) plasmin. Samples in all three groups were (left to right): $5 \mu \mathrm{l}$ of platelet poor plasma (platelet count $20 \times 10^{4} / \mathrm{l}$ ); $5 \mu \mathrm{l}$ of platelet poor plasma plus $5 \mu \mathrm{l}$ of platelet suspension (platelet count $120 \times$ $\left.10^{4} / l\right) ; 5 \mu$ of platelet suspension. 
inhibitors present in endothelial cell conditioned medium. ${ }^{15}$ Verheijen and colleagues have described an inhibitor of t-PA in plasma which, they conclude, is not derived from platelets, ${ }^{16}$ and the plasma inhibitor found by Wiman's group is of much higher molecular weight ${ }^{17}$ than that described here. The presence in platelets of an inhibitor of PA has also been shown recently by Erickson and colleagues by the same method as that used here. ${ }^{12}$ Inconsistencies between their results and ours may be explained by technical differences. For instance, they did not detect inhibition at $75 \mathrm{~K}$ in plasma or serum samples, though this inhibitor was consistently detected in our studies and identified as being due to $\alpha_{2^{-}}$ antiplasmin. ' While the concentration of u-PA in the detector gel is similar in the two laboratories, the time taken for complete lysis is strikingly different $(16 \mathrm{~h} v 2 \mathrm{~h})$, probably reflecting the difference in plasminogen concentration $(2.5 \mu \mathrm{g} / \mathrm{ml} v 25 \mu \mathrm{g} / \mathrm{ml})$.
This may explain differences in sensitivity between the two studies.

A number of recent reports on inhibitors of PA from endothelial cells indicate the similarity between the platelet and endothelial cell inhibitors. Erickson et al ${ }^{12}$ have shown the immunological relation between them. Other workers have noted the formation of a complex between the endothelial cell inhibitor and PA, ${ }^{12-20}$ similar in molecular weight to the complex we report here for the platelet inhibitor.

Although most of these inhibitors have been studied mainly in terms of their effects on t-PA, some of them also inhibit u-PA. ${ }^{21214}$ Clearly, comparative studies are required to establish the identities or otherwise of all these recently described inhibitors in respect of their immunology, cellular origin, and the nature of their molecular interactions with t-PA and u-PA.

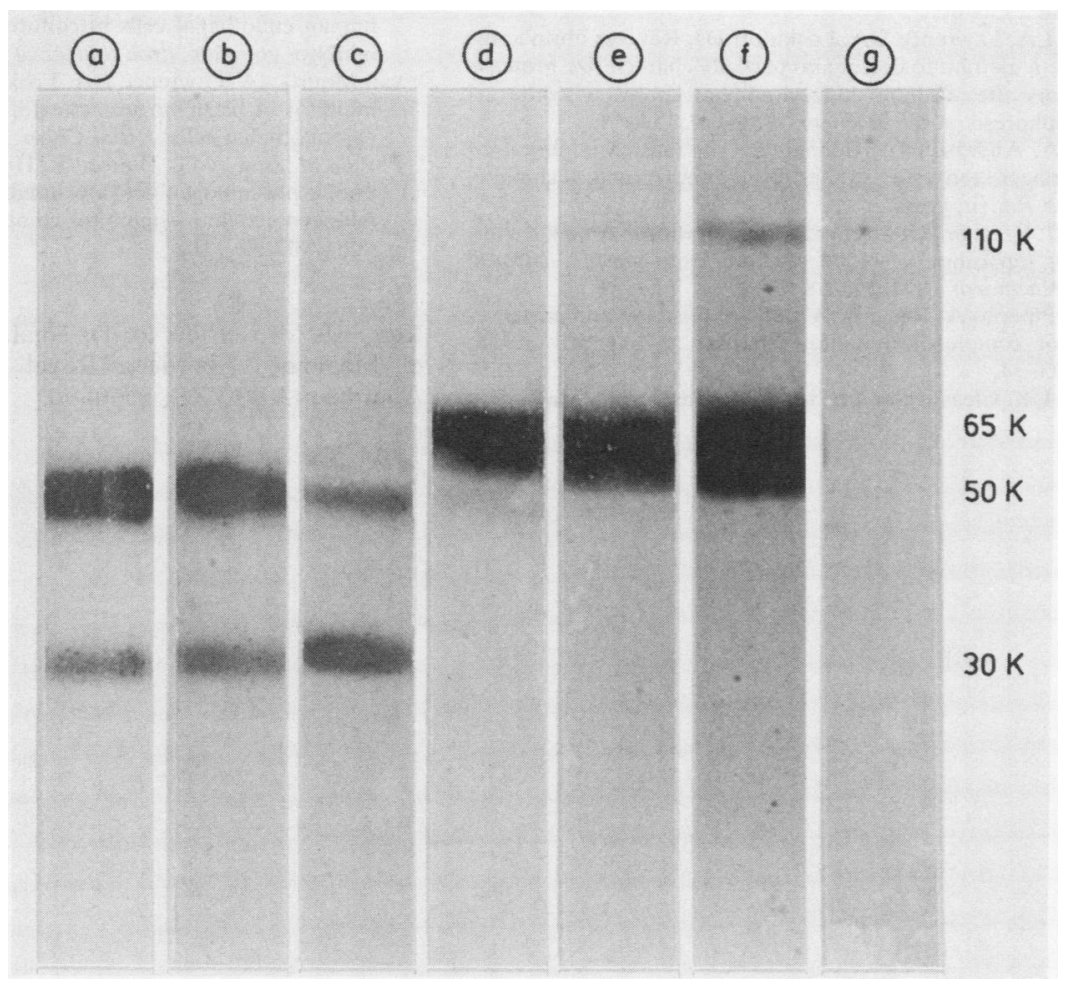

Fig. 4 Analysis of samples for plasminogen activator activity $(P A)$. Samples were incubated at $37^{\circ} \mathrm{C}$ for 5 min before addition of sample buffer and contained: (a) urokinase (u-PA) 0.1 Ploug unit; (b) u-PA 0.1 Ploug unit plus $20 \times 10^{4}$ lysed gel filtered platelets; (c) u-PA 0.1 Ploug unit plus $100 \times 10^{4}$ lysed gel filtered platelets; (d) tissue type plasminogen activator ( $t-P A) 0.01$ NIBSC unit; (e) $t-P A \quad 0.01$ NIBSC unit plus $20 \times 10^{4}$ lysed gel filtered platelets; $(f) t-P A 0.01$ NIBSC unit plus $100 \times$ $10^{4}$ lysed gel filtered platelets; $(g) 100 \times 10^{4}$ lysed gel filtered platelets. 
This study was supported by the Medical Research Council and the Scottish Home and Health Department. We thank Mrs Susan Beattie for excellent technical assistance and Mr John McIntosh of the Department of Medical Illustration for skilful photographic work.

\section{References}

' Collen D. On the regulation and control of fibrinolysis. Thromb Haemost 1980;43:77-89.

${ }^{2}$ Kruithof EKO, Tran-Thang C, Ransijn A, Bachmann F. Demonstration of a fast-acting inhibitor of plasminogen activators in human plasma. Blood 1984;64:907-13.

${ }^{3}$ Chmielewska J, Ranby M, Wiman B. Evidence for a rapid inhibitor to tissue plasminogen activator in plasma. Thromb Res 1983;31:427-36.

${ }^{4}$ Wijngaards G, Groeneveld E. Temporarily increased inhibition by plasma of plasminogen activator activity in severely ill patients. Haemostasis 1982;12:106.

' Loskutoff DJ, van Mourik JA, Erickson LA, Lawrence D. Detection of an unusually stable fibrinolytic inhibitor produced by bovine endothelial cells. Proc Natl Acad Sci USA 1983;80:2956-60.

- Erickson LA, Lawrence DA, Loskutoff DJ. Reverse fibrin autography: a method to detect and partially characterize protease inhibitors after sodium dodecyl sulphate-polyacrylamide gel electrophoresis. Anal Biochem 1984;137:454-63.

' Booth NA, Anderson JA, Bennett B. The plasma inhibitors of plasminogen activator, studied by a zymographic technique. Thromb Res (in press).

${ }^{8}$ Tangen O, Berman HJ, Marfey P. Gel filtration-A new technique for separation of blood platelets from plasma. Thromb Diath Haemorrh 1971;25:268-78.

${ }^{4}$ Granelli-Piperno A, Reich E. A study of protease and proteaseinhibitor complexes in biological fluids. J Exp Med 1978; 148: $223-34$.

${ }^{10}$ Laemmli UK. Cleavage of structural proteins during assembly of the head of bacteriophage T4. Nature (London) 1970; 227:680-5.

"Booth NA, Ligertwood Y, Bennett B. Molecular forms of plasminogen activator in human plasma. Progress in Fibrinolysis 1983;6:54-7.

12 Erickson LA, Ginsberg MH, Loskutoff DJ. Detection and partial characterization of an inhibitor of plasminogen activator in human platelets. J Clin Invest 1984; 74:1465-72.

${ }^{13}$ Booth NA, Anderson JA, Bennett B. Plasminogen activators in alcoholic cirrhosis: demonstration of increased tissue type and urokinase type activator. J Clin Pathol 1984;37:772-7.

14 Juhan-Vague I, Moerman B, de Cock F, Aillaud MF, Collen D. \&ै Plasma levels of a specific inhibitor of tissue-type plasminogen activator (and urokinase) in normal and pathological conditions. Thromb Res 1984;33:523-30.

is Sprengers ED, Verheijen JH, van Hinsbergh VWM, Emeis JJ. $\vec{\omega}$ Evidence for the presence of two different fibrinolytic inhibitors in human endothelial cell conditioned medium.? Biochim Biophys Acta 1984;801:163-70.

${ }^{10}$ Verheijen JH, Chang GTG, Kluft C. Evidence for the occurrence of a fast-acting inhibitor for t-PA in human plasma. Thromb Haemost 1984;51:392-5.

17 Wiman B, Chmielewska J, Ranby M. Inactivation of tissue plas- $\mathcal{G}$ minogen activator in plasma: demonstration of a complex with $\subseteq$ a new rapid inhibitor. J Biol Chem 1984;259:3644-7.

${ }^{18}$ Levin EG. Latent tissue plasminogen activator produced by human endothelial cells in culture: evidence for an enzymeinhibitor complex. Proc Natl Acad Sci USA 1983;80:6804-8.

${ }^{19}$ van Mourik JA, Lawrence DA, Loskutoff DJ. Purification of an inhibitor of plasminogen activator (antiactivator) synthesized by endothelial cells. J Biol Chem 1984;259:14914-21.

${ }^{20}$ Philips M, Juul A-G, Thorsen S. Human endothelial cells produce a plasminogen activator inhibitor and a tissue-type plasminogen activator-inhibitor complex. Biochim Biophys Acta 1984;802:99-110.

Requests for reprints to: Dr Nuala A Booth, Department of Medicine, Aberdeen Royal Infirmary, Foresterhill, Aberdeen AB9 2ZB, Scotland. 